\title{
Comparison of intraoperative tranexamic acid and epsilon-aminocaproic acid in cardiopulmonary bypass patients
}

\section{ABSTRACT}

Objective: To compare tranexamic acid (TXA) and epsilon-aminocaproic acid (EACA) in patients undergoing cardiac surgery with cardiopulmonary bypass.

Methods: Over a consecutive 2-year period, 824 adult cardiac surgery patients who received TXA during an EACA shortage were compared with 778 patients who received EACA postshortage. Patient characteristics and process and outcome variables were collected through chart review and database queries. This retrospective analysis used inverse probability of treatment weighting to control for confounding by indication, and propensity scores were calculated using a logistic regression model.

Results: In adjusted models, overall transfusion rates for the TXA cohort (odds ratio [OR], $0.94 ; 95 \%$ confidence interval [ $95 \% \mathrm{Cl}$ ], 0.81-1.10) and administration of platelets (OR, 1.04; 95\% Cl, 0.85-1.27), red blood cells (OR, 0.93; 95\% Cl, 0.80-1.09), fresh frozen plasma (OR, 1.00; $95 \% \mathrm{Cl}, 0.79-1.25)$, and cryoprecipitate (OR, 1.08; $95 \% \mathrm{Cl}, 0.71-1.64)$ were equivalent to the EACA cohort. In addition, there was no statistical difference with respect to stroke, seizure, mortality, reoperation for bleeding, chest tube drainage, and acute kidney injury. Patients who received TXA had shorter ventilator times (difference in medians -1.33 hours $[95 \% \mathrm{Cl}$, -1.86 to -0.80$]$ ) and lower postsurgical charges (difference of medians $-\$ 2913$ [95\% Cl, -5147 to -679$]$ ).

Conclusions: Substituting TXA for EACA during cardiac surgery with cardiopulmonary bypass did not change transfusion rate or amount, nor was there a significant difference in chest tube drainage. Patients who received TXA had a statistically significant but not clinically significant lower postoperative ventilator times and charges without an increase in mortality, stroke, reoperation for bleeding, acute kidney injury, or seizures. (JTCVS Open 2020;3:114-25)

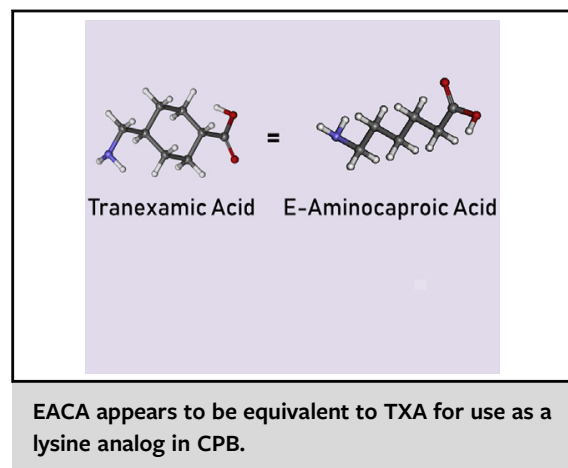

CENTRAL MESSAGE

TXA appears to be equivalent to EACA regarding transfusions and chest tube drainage with a statistically but clinically insignificant advantage regarding ventilator time and charges in CPB patients.

\section{PERSPECTIVE}

TXA appears to be equivalent to EACA in terms of transfusions administered and chest tube drainage. TXA patients spend less time on the ventilator postoperatively and have lower charges. Although these differences are statically significant, their clinical implications are minor

See Commentary on page 126.
The antifibrinolytic agents tranexamic acid (TXA) and epsilon-aminocaproic acid (EACA) are used in operations requiring cardiopulmonary bypass $(\mathrm{CPB})$. Since the BART

From the ${ }^{\mathrm{a} C a r d i o v a s c u l a r}$ Institute and ${ }^{\mathrm{c}}$ Department of Surgery, Maine Medical Center, Portland; and ${ }^{\mathrm{b}}$ Center for Outcomes Research and Evaluation, Maine Medical Center Research Institute, Scarborough, Me.

Received for publication May 8, 2020; revisions received May 8, 2020; accepted for publication May 15, 2020; available ahead of print June 23, 2020.

Address for reprints: Robert S. Kramer, MD, Maine Medical Center, 22 Bramhall St, Portland, ME 04102 (E-mail: kramer@mmc.org).

2666-2736

Copyright $@ 2020$ The Authors. Published by Elsevier Inc. on behalf of The American Association for Thoracic Surgery. This is an open access article under the CC BY-NC-

ND license (http://creativecommons.org/licenses/by-nc-nd/4.0/).

https://doi.org/10.1016/j.xjon.2020.05.003 trial, there have been multiple studies raising concerns of the dangers of aprotinin. ${ }^{1,2}$ It has become the standard of care to use TXA or EACA in these operations. ${ }^{1-4}$ Although much data exist comparing these lysine analogs with aprotinin, there are fewer data comparing them directly.

TXA has been adopted in the settings of trauma surgery, joint-replacement surgery, postpartum hemorrhage, and cardiac surgery. ${ }^{2,-10}$ TXA binds to plasminogen, which prevents its conversion to plasmin and its interaction with fibrin, ultimately stabilizing clot formation. ${ }^{4,8}$ Also, TXA has been shown to stabilize the endothelial glycocalyx, ${ }^{11,12}$ attenuate the inflammatory response in patients undergoing surgery with $\mathrm{CPB},{ }^{13}$ suppress the release of a damageassociated molecular pattern, mitochondrial DNA, in burn 


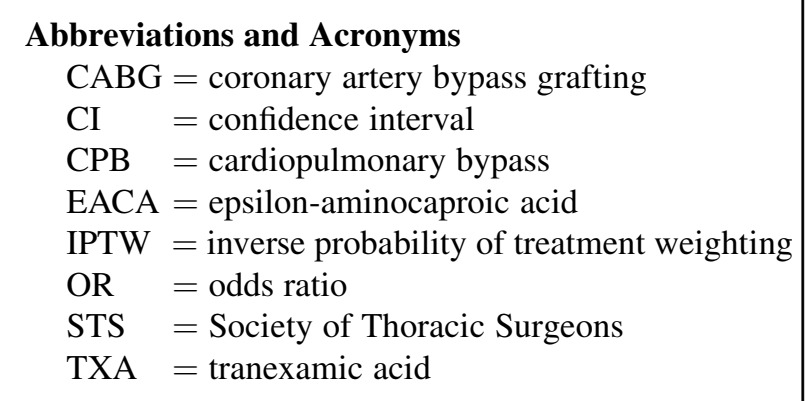

injuries, ${ }^{14}$ and binds to gamma-aminobutyric acid and glycine receptors in the central nervous system. ${ }^{15,16}$ Reports of seizures associated with TXA have discouraged its use in some programs. ${ }^{16}$

EACA also prevents the conversion of plasminogen to plasmin. EACA was first used clinically in urologic surgery and has since been used in multiple settings, including cardiac surgery, orthopedic surgery, neurosurgery, hepatobiliary surgery, and trauma surgery. ${ }^{6,8}$ EACA is recommended in guidelines of multiple professional societies in the setting of CPB. ${ }^{6,17,18}$

We explored the relative efficacy of TXA and EACA in the setting of CPB. From May 2013 to June 2014, an EACA shortage resulted in substituting TXA, creating an opportunity to do a retrospective analysis. We undertook this analysis using propensity scoring and other statistical strategies detailed in the following Methods section.

\section{METHODS}

We completed a retrospective analysis of a prospectively maintained database of adult cardiac surgeries from Maine Medical Center, a teaching hospital of Tufts University Medical School, where more than 1000 adult cardiac operations are performed annually by 6 cardiac surgeons. This cohort study was done in accordance with the STROBE (Strengthening the Reporting of Observational Studies in Epidemiology) Statement and reviewed by the Maine Medical Center institutional review board, who determined this analysis did not meet the definition of research as specified under 45 CFR 46.111 and 21 CFR 56.111. Patients included were those who were operated on in the time frame when TXA was used, May 2013 to June 3, 2014, and the time frame when EACA was used, June 4, 2014 to May 2015. Also included in this study were those patients older than 18 years of age who underwent cardiac surgery that required CPB during the time period of May 2013 to May 2015 and received either TXA or EACA intraoperatively. Any subject who did not meet the aforementioned criteria, who underwent off-pump surgery, did not have an antifibrinolytic agent administered, had a history of a coagulation disorder (such as inherited genetic disorders, cancer or severe liver disease), or died in the operating room was excluded.

In total, 1773 patients were identified as undergoing cardiac surgery during the predefined time frames. After we screened for exclusion criteria, a total of 1602 patients met eligibility requirements (Figure 1). Of the 1602 adult cardiac surgery patients, 824 received TXA during the EACA shortage period and were compared with 778 patients who received EACA after the shortage was resolved in the second time period analyzed and thus was random based only on when an individual patient received surgery.

With regard to the conduct of cardiopulmonary bypass (CPB) for both groups, the prime was composed of Normosol-R. The volume varied according to circuit size; $1160 \mathrm{cc}$ was used for the standard circuit and $1060 \mathrm{cc}$ for the small circuit. Retrograde autologous priming was used in $54 \%$ of patients who received TXA and $52 \%$ who received EACA. The LivaNova Circuit with Inspire reservoir and oxygenator (LivaNova, London,

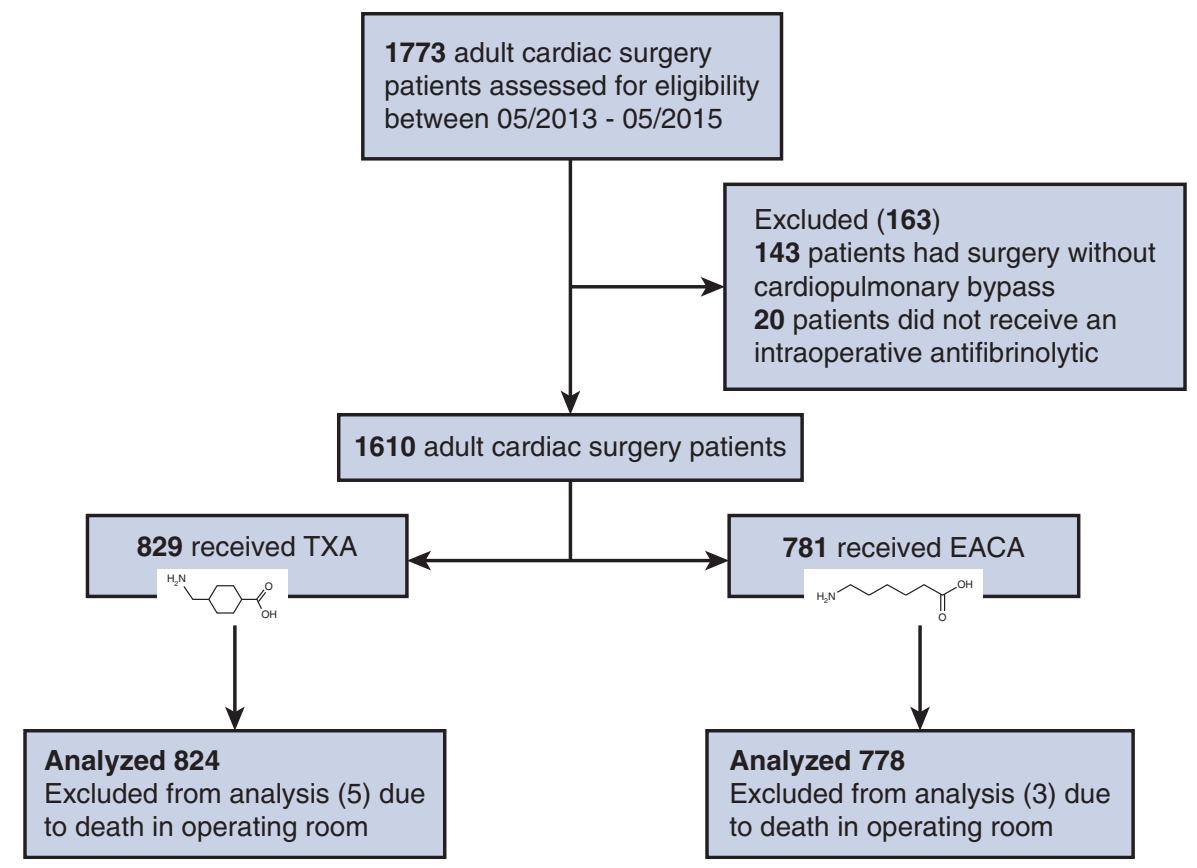

FIGURE 1. The Consolidated Standards of Reporting Trial Flow Diagram. A total of 1773 patients were identified in the institutional database who had undergone cardiac surgery during the era studied. After exclusion of subjects per specified criteria 1610 patients remained. Analysis was completed on 824 patients receiving TXA, whereas 778 received EACA (8 patients removed from analysis due to death in the operating room). TXA, Tranexamic acid; EACA, epsilon-aminocaproic acid. 
United Kingdom) were used on all patients. Acute normovolemic hemodilution was not used on any patients. For myocardial protection, microplegia was used, the arrest dose being $22 \mathrm{mEq}$ of $\mathrm{KCL} / \mathrm{L}$ mixed with $\mathrm{MgSO}_{4}$ and the patients' blood through the Quest MPS platform. Heparin administration was guided by a weight-based formula in all patients with a target activated clotting time of 480 seconds. The open-heart coagulation panel consists of partial thromboplastin time, international normalized ratio, platelet count, and fibrinogen drawn after protamine reversal of heparin and repeated as necessary. Product administration (platelets, cryoprecipitate, and fresh frozen plasma) during both time periods was based on the clinical setting, coagulation panel, and the discretion of the treating surgical, anesthesia, perfusion, or intensive care unit teams in both groups. Corticosteroids were administered only when specifically indicated. The Fresenius Kabi C.A.T.S plus Continuous AutoTransfusion System (Terumo Cardiovascular, Ann Arbor, Mich) was used to salvage shed blood when the patients were not heparinized; otherwise, the cardiotomy suction was used in the heparinized patient to return blood to the CPB circuit. Residual pump volume was bagged and returned to the patient at the end of CPB. Intraoperative volume administered averaged approximately $1600 \mathrm{~mL}$ in the TXA cohort and $1700 \mathrm{~mL}$ in the EACA cohort.

A transfusion protocol was used to guide transfusion practice. "Guidelines for Adult RBC Transfusions" were in place during the time of this analysis and are incorporated into the EMR as decision support with 3 indications as follows: (1) clinically significant acute blood loss; (2) hemoglobin $<7 \mathrm{~g} / \mathrm{dL}$ (or hematocrit $<21 \%$ ), and (3) hemoglobin $<8 \mathrm{~g} / \mathrm{dL}$ (or hematocrit $<24$ ) and hemodynamically unstable.

Regarding standards of practice and protocols, many of the decisions in the cardiothoracic intensive care unit are protocol driven, particularly red blood cell transfusions and extubation. Discharge from cardiothoracic intensive care unit is by consensus from the multidisciplinary group, with minimal variation from patient to patient and between time periods analyzed. Patient extubation is protocol-driven by a nurse and a respiratory therapist with input from the surgeon, advanced practice provider, or intensivist as necessary.

The primary outcomes were mortality during the index admission, stroke, acute kidney injury (defined by the Acute Kidney Injury Network ${ }^{19}$ ), need for reoperation, 24-hour postoperative chest tube output, blood products received (intraoperatively and postoperatively), and seizures. Secondary outcomes were postoperative length of stay, intensive care unit length of stay, total postoperative ventilation hours, and hospital charges.

The majority of data was collected from a prospectively maintained cardiac surgery database as defined by the Society of Thoracic Surgeons (STS) and submitted to the STS database and the Northern New England Cardiovascular Diseases Study Group database. Both databases are validated at regular intervals. A list of patients was obtained from the Cardiac Surgery Database who had surgery during the time frame of May 2013 through May 2015. Information that was not present in the database was manually abstracted through chart review in the electronic record (EPIC Systems Corp, Verona, Wis).

The manually abstracted data included postoperative seizures for the entire time frame of May 2013 through May 2015, chest tube output for the time frame of May 2013 through June 2014, and additional data points. The finance department completed the economic data from which charges were derived. Cost data were available for part of the time period whereas charges were available for the entire period; therefore, we report charges. The finance department extracted all services using the chargemaster code with the date of service, revenue code, and related expense using cost accounting and budgeting software StrataJazz (Strata Decision Technology, Chicago, Ill). Charges did not change over the time period in question and represent those charges incurred during the index hospitalization. TXA cost (\$35.76/dose) was similar to the EACA cost (\$29.80/dose). All services were cross-referenced to the medical record number and date of surgery at which point all services provided after the date of surgery were accounted for in the charge summary. All abstracted data were reviewed for validity and accuracy before analysis. All manual data abstraction occurred within the confines of Maine Medical Center hospital and all data were deidentified once data collection was complete.

We examined the distribution of all variables using proportions for categorical variables and means (standard deviations) and medians (interquartile ranges) for continuous variables (Table 1). Continuous variables were evaluated for normality using tests of skewness and kurtosis. Because all continuous variables of interest were not normally distributed, we used nonparametric techniques for reporting and analysis purposes. We treated transfusion data as both binary and using a count of the number of units transfused. We compared treatment groups using $\chi^{2}$ tests for categorical variables and tests for differences in distributions (Mann-Whitney $U$ test) for continuous and count variables.

We used inverse probability of treatment weighting (IPTW) to adjust for treatment selection bias in this observational study. The IPTW uses a propensity score, a subject's probability of treatment selection conditioned on observed baseline covariates. Inverse probability weighting is used to assess associations of outcomes with treatments when the researcher cannot conduct a controlled (randomized) experiment. Weighting subjects by the inverse probability of the treatment received creates a synthetic sample in which treatment assignment is independent of measured baseline covariates. $^{20}$

Propensity scores were calculated using a logistic regression model, with treatment assignment as the dependent variable and all patient characteristics that differed between treatment groups with a $P$ value of .25 or less as covariates. In addition, we forced age and sex into the model and, because our primary outcomes were transfusion related, we included preoperative hematocrit, even though it did not meet our inclusion threshold. We did not include STS risk scores in the propensity score model because these variables were missing for any patient who had a surgery that was neither coronary artery bypass grafting (CABG) nor valve nor a combined $\mathrm{CABG} /$ valve procedure, therefore not missing at random and not amenable to imputation. We then used inverse probability of treatment weights derived from the propensity score model in adjusted analyses. In addition, we observed treatment differences by surgeon, based on staff changes. When able, we controlled for surgeon in our models; for certain outcomes (especially rare binary outcomes), models including surgeon did not converge, so surgeon had to be excluded from these models. We used logistic regression models for categorical outcomes, negative binomial models for count models, and quantile regression comparing medians for continuous outcomes, all using the IPTW weights. Logistic regression models resulted in odds ratios (OR) and $95 \%$ confidence intervals (CIs) comparing TXA with EACA; negative binomial models resulted in rate ratios with $95 \%$ CIs; quantile regression resulted in differences in medians and $95 \%$ CIs. Analyses were performed using SPSS version 20 (IBM Corp, Armonk, NY) and SAS EG version 7.1 (SAS Institute, Cary, NC).

We tested the performance of Poisson, negative binomial, and ordinal logistic models for number of transfusions. We did not fit zero-inflated Poisson or negative binomial data because we believe that there is no justification for assuming structural zeros in transfusion data (that is, there is no cardiac surgery patient who is not at risk of transfusion). There was clear evidence of overdispersion in the Poisson models. Using the log likelihood and AIC criteria, the negative binomial models fit the data best and we report rate ratio estimates from these models. When outcomes were binary (that is, the only 2 values for the number of transfusions was either 0 or 1), we used logistic regression models to estimate ORs.

\section{RESULTS}

The 2 groups were well balanced with regards to age, sex, diabetes, chronic lung disease, preoperative he- 
TABLE 1. Crude outcomes

\begin{tabular}{|c|c|c|c|}
\hline Outcome & EACA & TXA & $P$ value \\
\hline \multicolumn{4}{|l|}{$\mathrm{n}(\%)$} \\
\hline Mortality & $19(2 \%)$ & $17(2 \%)$ & .73 \\
\hline Stroke & $15(2 \%)$ & $18(2 \%)$ & .85 \\
\hline Acute kidney injury & $194(25 \%)$ & $205(25 \%)$ & 1.00 \\
\hline Reoperation (bleeding) & $36(5 \%)$ & $40(5 \%)$ & .92 \\
\hline Any transfusion & $312(40 \%)$ & $287(35 \%)$ & .03 \\
\hline Red blood cells & $282(36 \%)$ & $259(31 \%)$ & .04 \\
\hline Platelets & $127(16 \%)$ & $111(13 \%)$ & .12 \\
\hline Fresh frozen plasma & $99(13 \%)$ & $83(10 \%)$ & .11 \\
\hline Cryoprecipitate & $26(3 \%)$ & $19(2 \%)$ & .27 \\
\hline \multicolumn{4}{|l|}{ Intraoperative transfusion } \\
\hline Any transfusion & $161(21 \%)$ & $137(17 \%)$ & .04 \\
\hline Red blood cells & $109(14 \%)$ & $103(13 \%)$ & .40 \\
\hline Platelets & $91(12 \%)$ & $65(8 \%)$ & .01 \\
\hline Fresh frozen plasma & $67(9 \%)$ & $48(6 \%)$ & .04 \\
\hline Cryoprecipitate & $7(1 \%)$ & $6(1 \%)$ & .91 \\
\hline \multicolumn{4}{|l|}{ Postoperative transfusion } \\
\hline Any transfusion & $269(35 \%)$ & $241(29 \%)$ & .02 \\
\hline Red blood cells & $256(33 \%)$ & $220(27 \%)$ & .007 \\
\hline Platelets & $61(8 \%)$ & $66(8 \%)$ & .99 \\
\hline Fresh frozen plasma & $50(6 \%)$ & $50(6 \%)$ & .84 \\
\hline Cryoprecipitate & $20(3 \%)$ & $14(2 \%)$ & .30 \\
\hline Neosynephrine $48 \mathrm{~h}$ & $51(6 \%)$ & $79(10 \%)$ & .03 \\
\hline Vasopressors $48 \mathrm{~h}$ & $82(11 \%)$ & $120(15 \%)$ & .02 \\
\hline \multicolumn{4}{|l|}{ Median (interquartile range) } \\
\hline Postsurgery length of stay, $d$ & $6(5,8)$ & $6(5,8)$ & .01 \\
\hline ICU length of stay, $h$ & $27(19.5,54)$ & $27(20,52.5)$ & .97 \\
\hline Postoperative vent time, $\mathrm{h}$ & $7(5,12)$ & $5.6(4.1,9.4)$ & $<.0001$ \\
\hline 24-h chest tube drainage, $\mathrm{mL}$ & $600(440,840)$ & $620(440,900)$ & .21 \\
\hline Charges, \$US & $23,605(15,081,41,332)$ & $20,126(12,978,36,288)$ & $<.0001$ \\
\hline \multicolumn{4}{|l|}{ Intraoperative transfusion (units) } \\
\hline Red blood cells & $0(0,0)$ & $0(0,0)$ & .35 \\
\hline Platelets & $0(0,0)$ & $0(0,0)$ & .01 \\
\hline Fresh frozen plasma & $0(0,0)$ & $0(0,0)$ & .03 \\
\hline Cryoprecipitate & $0(0,0)$ & $0(0,0)$ & .70 \\
\hline \multicolumn{4}{|l|}{ Postoperative transfusion (units) } \\
\hline Red blood cells & $0(0,1)$ & $0(0,1)$ & .001 \\
\hline Platelets & $0(0,0)$ & $0(0,0)$ & .72 \\
\hline Fresh frozen plasma & $0(0,0)$ & $0(0,0)$ & .77 \\
\hline Cryoprecipitate & $0(0,0)$ & $0(0,0)$ & .22 \\
\hline
\end{tabular}

EACA, Epsilon-aminocaproic acid; TXA, tranexamic acid; $I C U$, intensive care unit.

matocrit, preoperative platelets, previous cardiac surgery, preoperative platelet therapy, or type of cardiac surgery (Table 2).

In adjusted models, TXA use was not associated with a lower overall transfusion rate (OR, 0.94; 95\% CI, 0.811.10; Table 3). Patients who received TXA were not less likely to receive platelets (OR, 1.04; 95\% CI, 0.85, 1.27; Table 3), red blood cells (OR, 0.93; 95\% CI, 0.80-1.09), fresh frozen plasma (OR, 1.00; 95\% CI, 0.79-1.25), or cryoprecipitate (OR, 1.08; 95\% CI, 0.71-1.64). It is clear from this analysis that the patients in the TXA group were just as likely to be transfused as those in the EACA group
(Figure 2). In addition, postoperative hematocrits in both groups were not different post operatively and closest to discharge (Table 4). No difference was seen in rates of stroke, mortality, reoperation for bleeding, chest tube drainage, and acute kidney injury. As a result of the low incidence of seizures in both cohorts, no seizures in EACA and 1 seizure in the TXA cohort, we can only state that there did not appear to be an increased risk of seizure when comparing TXA with EACA.

The groups did not differ in postoperative length of stay, intensive care unit length of stay, and 24-hour chest tube drainage. Patients who received TXA had shorter ventilator 
TABLE 2. Demographic, preoperative, and procedure comparisons

\begin{tabular}{|c|c|c|c|c|c|c|}
\hline \multirow[b]{2}{*}{ Demographic characteristics } & \multicolumn{3}{|c|}{ Unadjusted values } & \multicolumn{3}{|c|}{ Inverse probability of treatment- weighted values } \\
\hline & EACA $(n=778)$ & TXA $(n=824)$ & $P$ value & EACA $(n=778)$ & TXA $(n=824)$ & $P$ value \\
\hline Atrial fibrillation/flutter, $\mathrm{n}(\%)$ & $164(21 \%)$ & $138(17 \%)$ & .03 & $19 \%$ & $19 \%$ & .90 \\
\hline Aortic procedure, $\mathrm{n}(\%)$ & $76(10 \%)$ & $78(9 \%)$ & .90 & $10 \%$ & $10 \%$ & .51 \\
\hline Congestive heart failure, $\mathrm{n}(\%)$ & $259(33 \%)$ & $343(42 \%)$ & .0007 & $38 \%$ & $38 \%$ & .97 \\
\hline Cardiogenic shock, n (\%) & $23(3 \%)$ & $10(1 \%)$ & .02 & $2 \%$ & $2 \%$ & .87 \\
\hline Chronic lung disease, $\mathrm{n}(\%)$ & $190(24 \%)$ & $152(18 \%)$ & .004 & $21 \%$ & $21 \%$ & .92 \\
\hline $\begin{array}{l}\text { Circulatory arrest during operation, } \\
\mathrm{n}(\%)\end{array}$ & $24(3 \%)$ & $25(3 \%)$ & 1.00 & $3 \%$ & $3 \%$ & .74 \\
\hline Diabetes, n (\%) & $264(34 \%)$ & $297(36 \%)$ & .41 & $35 \%$ & $36 \%$ & .31 \\
\hline Female sex, n $(\%)$ & $219(28 \%)$ & $235(29 \%)$ & .91 & $29 \%$ & $29 \%$ & .95 \\
\hline $\begin{array}{l}\text { Anticoagulation (coumadin, heparin), } \\
\mathrm{n}(\%)\end{array}$ & $373(48 \%)$ & $361(44 \%)$ & .11 & $46 \%$ & $46 \%$ & .88 \\
\hline Hypertension, ${ }^{*} \mathrm{n}(\%)$ & $616(79 \%)$ & $662(80 \%)$ & .64 & $79 \%$ & $80 \%$ & .46 \\
\hline Left ventricular assist device, $\mathrm{n}(\%)$ & $4(0.5 \%)$ & $0(0 \%)$ & .06 & $0.6 \%$ & $0 \%$ & .003 \\
\hline Thrombolytic, n (\%) & $2(0.3 \%)$ & $8(1 \%)$ & .11 & $0.6 \%$ & $0.6 \%$ & .87 \\
\hline Peripheral vascular disease, $\mathrm{n}(\%)$ & $104(13 \%)$ & $114(14 \%)$ & .84 & $13 \%$ & $14 \%$ & .73 \\
\hline $\begin{array}{l}\text { Cerebrovascular disease (CVA, TIA), } \\
\mathrm{n}(\%)\end{array}$ & $98(13 \%)$ & $82(10 \%)$ & .11 & $11 \%$ & $11 \%$ & .93 \\
\hline \multicolumn{7}{|l|}{ Antiplatelet therapy, n (\%) } \\
\hline Aspirin & $681(88 \%)$ & $766(93 \%)$ & .0003 & $90 \%$ & $90 \%$ & .74 \\
\hline GP IIb/IIIa inhibitor & $7(1 \%)$ & $16(2 \%)$ & .12 & $1 \%$ & $1 \%$ & .86 \\
\hline ADP receptor inhibitor & $23(3 \%)$ & $31(4 \%)$ & .45 & $4 \%$ & $3 \%$ & .71 \\
\hline Preoperative dialysis, $\mathrm{n}(\%)$ & $13(2 \%)$ & $18(2 \%)$ & .57 & $2 \%$ & $2 \%$ & .84 \\
\hline $\begin{array}{l}\text { Previous acute myocardial infarction, } \dagger \\
\text { n }(\%)\end{array}$ & $344(44 \%)$ & $375(46 \%)$ & .67 & $44 \%$ & $46 \%$ & .23 \\
\hline Previous cardiac surgery, n (\%) & $57(7 \%)$ & $44(5 \%)$ & .13 & $6 \%$ & $6 \%$ & .97 \\
\hline Statin therapy, n (\%) & $617(79 \%)$ & $656(80 \%)$ & .93 & $80 \%$ & $79 \%$ & .59 \\
\hline Priority, n (\%) & & & .25 & & & 1.00 \\
\hline Elective & $354(46 \%)$ & $360(44 \%)$ & & $44 \%$ & $44 \%$ & \\
\hline Emergent & $43(6 \%)$ & $34(4 \%)$ & & $5 \%$ & $5 \%$ & \\
\hline Urgent & $381(49 \%)$ & $430(52 \%)$ & & $51 \%$ & $51 \%$ & \\
\hline Steroids, n (\%) & $21(3 \%)$ & $27(3 \%)$ & .60 & $2 \%$ & $3 \%$ & .27 \\
\hline Surgeon, $\mathrm{n}(\%)$ & & & $<.0001$ & & & $<.0001$ \\
\hline 1 & $189(24 \%)$ & $236(29 \%)$ & & $27 \%$ & $28 \%$ & \\
\hline 2 & $232(30 \%)$ & $100(12 \%)$ & & $29 \%$ & $12 \%$ & \\
\hline 3 & $182(23 \%)$ & $176(21 \%)$ & & $22 \%$ & $23 \%$ & \\
\hline 4 & $175(22 \%)$ & $201(24 \%)$ & & $23 \%$ & $23 \%$ & \\
\hline 5 & $0(0 \%)$ & $103(13 \%)$ & & $0 \%$ & $12 \%$ & \\
\hline 6 & $0(0 \%)$ & $8(1 \%)$ & & $0 \%$ & $1 \%$ & \\
\hline Surgery type, n (\%) & & & .77 & & & 1.00 \\
\hline Isolated CABG & $423(54 \%)$ & $443(54 \%)$ & & $54 \%$ & $54 \%$ & \\
\hline Isolated valve & $123(16 \%)$ & $136(17 \%)$ & & $16 \%$ & $16 \%$ & \\
\hline CABG/single valve & $77(10 \%)$ & $92(11 \%)$ & & $11 \%$ & $11 \%$ & \\
\hline Other & $155(20 \%)$ & $153(19 \%)$ & & $19 \%$ & $19 \%$ & \\
\hline Hemoglobin A1C $(\%), \ddagger$ median (IQR) & $5.9(5.6,6.6)$ & $5.9(5.6,6.7)$ & .90 & $5.9(5.6,6.6)$ & $5.9(5.6,6.7)$ & 1.00 \\
\hline Age, y, median (IQR) & $67(58,74)$ & $67(59,74)$ & .75 & $67(58,74)$ & $67(59,74)$ & 1.00 \\
\hline Body surface area, $\mathrm{kg} / \mathrm{m}^{2}$, median (IQR) & $2.0(1.9,2.2)$ & $2.0(1.9,2.2)$ & .31 & $2.0(1.9,2.2)$ & $2.0(1.9,2.2)$ & .58 \\
\hline
\end{tabular}


TABLE 2. Continued

\begin{tabular}{|c|c|c|c|c|c|c|}
\hline \multirow[b]{2}{*}{ Demographic characteristics } & \multicolumn{3}{|c|}{ Unadjusted values } & \multicolumn{3}{|c|}{ Inverse probability of treatment- weighted values } \\
\hline & EACA $(n=778)$ & TXA $(n=824)$ & $P$ value & EACA $(n=778)$ & TXA $(n=824)$ & $P$ value \\
\hline $\begin{array}{l}\text { Cardiopulmonary bypass time, } \\
\text { min, median (IQR) }\end{array}$ & $110(87,140)$ & $103(81,133)$ & .001 & $106(85,135)$ & $106(83,140)$ & 1.00 \\
\hline Hematocrit (\%), median (IQR) & $40(36,43)$ & $40(36,42)$ & .27 & $40(36,43)$ & $40(36,43)$ & .76 \\
\hline Platelets, thousands $/ \mu \mathrm{L}$, median (IQR) & $207.0(170.0,253.0)$ & $201.0(168.0,242.5)$ & .11 & $250.0(169.0,248.0)$ & $203.0(169.0,248.0)$ & .55 \\
\hline Creatinine, ${ }^{*} \mathrm{mg} / \mathrm{dL}$, median (IQR) & $0.96(0.80,1.15)$ & $0.96(0.80,1.12)$ & .37 & $0.96(0.80,1.15)$ & $0.95(0.80,1.11)$ & .52 \\
\hline $\begin{array}{l}\text { STS major morbidity/mortality } \\
\text { score, } \%, \S \text { median (IQR) }\end{array}$ & $13.2(8.7,21.2)$ & $12.3(8.2,21.0)$ & .17 & $13(9,21)$ & $12(8,21)$ & .20 \\
\hline STS mortality score, $\%, \S$ median (IQR) & $1.34(0.74,2.91)$ & $1.36(0.69,3.08)$ & .45 & $1.33(0.74,2.97)$ & $1.36(0.69,3.05)$ & .81 \\
\hline
\end{tabular}

Data are presented as median $(25 \%, 75 \%)$ for continuous variables and n $(\%)$ for categoric data. EACA, Epsilon-aminocaproic acid; TXA, tranexamic acid; $C V A$, cerebrovascular accident; TIA, transient ischemic attack; GP, glycoprotein; $A D P$, adenosine $5^{\prime}$-diphosphate; $C A B G$, coronary artery bypass grafting; $I Q R$, interquartile range; STS, Society of Thoracic Surgeons. *Data missing, 1. †Data missing, 2. §Data missing, 268. †Data missing, 70.

times (difference in medians -1.33 hours [95\% CI -1.86 to -0.80$]$ ), and lower postsurgical charges (difference of medians $-\$ 2913$ [ -5147 to -679$]$; Table 5 and Figure $3)$. The postsurgical charge difference represents savings of more than $\$ 2.8$ million annually, and the difference of time on the ventilator annualized to approximately 1300 hours. The TXA cohort had greater rates of an active vasoconstrictor infusion at the 48 -hour postoperative time

TABLE 3. Effect of TXA relative to EACA on cardiac surgery outcomes

\begin{tabular}{|c|c|c|}
\hline Outcome & Crude TXA effect & IPTW TXA effect* \\
\hline \multicolumn{3}{|l|}{ Odds ratios $(95 \% \mathrm{CI})$} \\
\hline Mortality & $0.83(0.43-1.61)$ & $1.03(0.64-1.65) \dagger$ \\
\hline Stroke & $1.12(0.56-2.24)$ & $1.49(0.90-2.47) \dagger$ \\
\hline Acute kidney injury & $0.99(0.79-1.25)$ & $0.98(0.83-1.16)$ \\
\hline Reoperation (bleeding) & $1.09(0.69-1.74)$ & $1.18(0.85-1.62) \dagger$ \\
\hline Any transfusion & $0.79(0.65-0.97)$ & $0.94(0.81-1.10)$ \\
\hline Red blood cells & $0.80(0.65-0.99)$ & $0.93(0.80-1.09)$ \\
\hline Platelets & $0.80(0.60-1.05)$ & $1.04(0.85-1.27)$ \\
\hline Fresh frozen plasma & $0.77(0.57-1.05)$ & $1.00(0.79-1.25)$ \\
\hline Cryoprecipitate & $0.68(0.37-1.24)$ & $1.08(0.71-1.64)$ \\
\hline \multicolumn{3}{|l|}{ Intraoperative transfusion } \\
\hline Any transfusion & $0.77(0.60-1.00)$ & $1.00(0.84-1.21)$ \\
\hline Red blood cells & $0.90(0.67-1.20)$ & $1.12(0.91-1.38)$ \\
\hline Platelets & $0.65(0.46-0.90)$ & $0.80(0.63-1.01) \dagger$ \\
\hline Fresh frozen plasma & $0.67(0.46-0.98)$ & $0.86(0.66-1.12) \dagger$ \\
\hline Cryoprecipitate & $0.81(0.27-2.41)$ & $1.07(0.54-2.09) \dagger$ \\
\hline \multicolumn{3}{|l|}{ Postoperative transfusion } \\
\hline Any transfusion & $0.78(0.63-0.96)$ & $0.92(0.79-1.08)$ \\
\hline Red blood cells & $0.74(0.60-0.92)$ & $0.87(0.74-1.02)$ \\
\hline Platelets & $1.04(0.72-1.49)$ & $1.24(0.95-1.63)$ \\
\hline Fresh frozen plasma & $0.92(0.62-1.38)$ & $1.16(0.86-1.57)$ \\
\hline Cryoprecipitate & $0.65(0.33-1.30)$ & $0.82(0.51-1.31) \dagger$ \\
\hline Phenylephrine $48 \mathrm{~h}$ & $1.49(1.03-2.15)$ & $1.35(1.04-1.76)$ \\
\hline Vasopressin $48 \mathrm{~h}$ & $1.49(1.11-2.02)$ & $1.35(1.08-1.68)$ \\
\hline \multicolumn{3}{|l|}{ Differences in medians $(95 \% \mathrm{CI})$} \\
\hline Post-surgery length of stay, d & $0(-0.30,0.30)$ & $0(-0.37,0.37)$ \\
\hline ICU length of stay, h & $-0.50(-3.20,2.20)$ & $0(-2.69,2.69)$ \\
\hline Postoperative ventilator time, $\mathrm{h}$ & $-1.37(-1.87,-0.87)$ & $-1.33(-1.86,-0.80)$ \\
\hline 24-h chest tube drainage, $\mathrm{mL}$ & $20(-21,61)$ & $15(-27.3,57.3)$ \\
\hline Charges, \$US & $-3475(-5631,-1320)$ & $-2913(-5147,-679)$ \\
\hline
\end{tabular}

$T X A$, Tranexamic acid; $I P T W$, inverse probability of treatment weighting; $C I$, confidence interval; $I C U$, intensive care unit. *Adjusted for surgeon. $\dagger$ No adjustment for surgeon due to quasi-separation. 


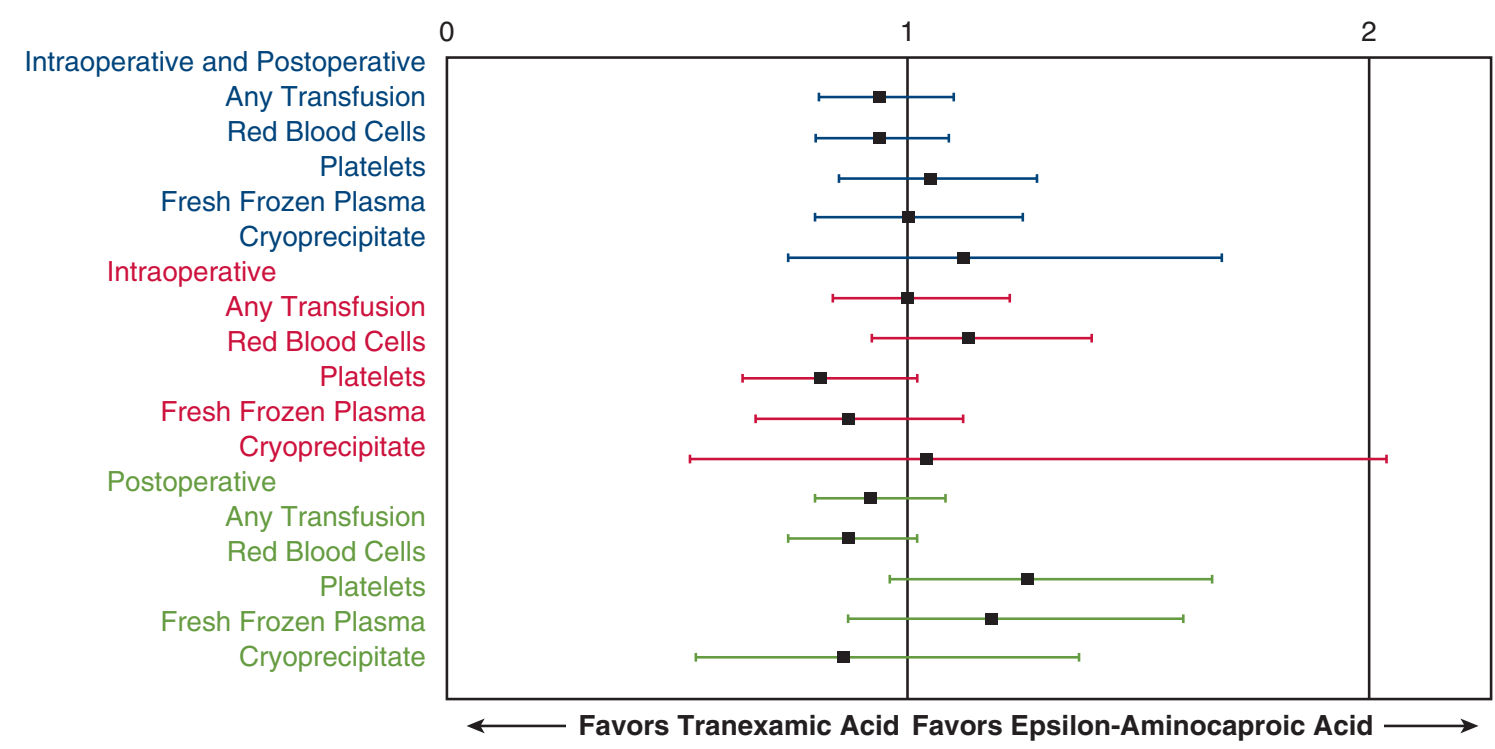

FIGURE 2. Forest plot of odds ratio and $95 \%$ confidence intervals for blood product transfusions during the combined intraoperative/postoperative period (blue text), intraoperative period (red text), and postoperative period (green text) in cardiac surgery patients on cardiopulmonary bypass.

point: phenylephrine (OR, 1.35 [95\% CI, 1.04-1.76]) and vasopressin (OR, 1.35 [95\% CI, 1.08-1.68]; Table 3).

\section{DISCUSSION}

TXA was associated with less postoperative ventilator time, and lower hospital charges without an increase in mortality, stroke, reoperation for bleeding, acute kidney injury, or seizures. TXA and EACA appear to be equivalent as antifibrinolytic agents in the setting of cardiac surgery patients undergoing operations with CPB.

Administration of antifibrinolytic agents during CPB lowers both the blood loss and need for red blood cell transfusion, ${ }^{2,21}$ but there are few data directly comparing the efficacy of TXA and EACA on transfusion burden with four studies directly comparing the two. ${ }^{5,7,22,23}$ Although TXA is more commonly used worldwide, EACA is still used in the United States ${ }^{24}$ and was used until recently in our center, where we now favor TXA. TXA is a more potent antifibrinolytic than EACA. ${ }^{17}$

Despite there being no change in transfusion requirements or chest tube drainage in either group after the extensive adjustments made in this analysis, time on the ventilator and charges stood out significantly, when annualized, but were small differences for individual patients, the central message being that we found very little difference between TXA and EACA (Tables 3 and 6).

Raghunathan and colleagues ${ }^{22}$ reanalyzed the data from the BART and found no significant difference in any outcome except for a mild reduction in relative risk of transfusion of fresh frozen plasma in patients who received TXA when compared with those who received EACA. Makhija and colleagues ${ }^{7}$ found no significant difference in transfusion requirement between the TXA and EACA treatment arms. Falana and Patel ${ }^{5}$ in a study of 120 CPB patients treated with either TXA or EACA found that in a subgroup of patients requiring a massive transfusion the difference was not statistically significant. In 2000 Maineri and colleagues $^{23}$ determined that either drug can be safely used in cardiac surgery but had no statistically significant difference in postoperative bleeding or requirement of homologous blood between the groups treated with TXA or EACA.

Hospital stay mortality rate did not differ between cohorts, consistent with other studies on this subject. ${ }^{5,7,22}$ Our study was limited in scope and did not collect

TABLE 4. Hematocrit values from quantile regression, differences in medians with propensity score adjustment

\begin{tabular}{llllr}
\hline Hematocrit, median (interquartile range) & EACA & TXA & P value & $\begin{array}{c}\text { IPTW-adjusted difference in } \\
\text { medians (95\% confidence interval) }\end{array}$ \\
\hline Preoperative & $40(36,43)$ & $40(36,42)$ & .27 & $0.10(-0.53$ to 0.73$)$ \\
Nadir & $25(21,28)$ & $24(21,27)$ & .001 & $-1.00(-1.61$ to -0.39$)$ \\
Postoperative & $32(28,35)$ & $31(28,35)$ & .12 & $-0.50(-1.23$ to 0.23$)$ \\
Closest to discharge & $29(26,32)$ & $29(26,32)$ & .47 & $-0.40(-1.00$ to 0.20$)$ \\
\hline
\end{tabular}

EACA, Epsilon-aminocaproic acid; TXA, tranexamic acid; IPTW, inverse probability of treatment. 
TABLE 5. Distributions of unadjusted ventilator time hours and postoperative charges in US dollar currency by antifibrinolytic received

\begin{tabular}{lccc}
\hline $\begin{array}{c}\text { Variable distributional } \\
\text { characteristics }\end{array}$ & $\begin{array}{c}\text { EACA } \\
(\mathbf{n}=\mathbf{7 7 8})\end{array}$ & $\begin{array}{c}\text { TXA } \\
(\mathbf{n}=\mathbf{8 2 4})\end{array}$ & $\begin{array}{c}\boldsymbol{P} \\
\text { value }\end{array}$ \\
\hline Ventilator hours & 2368 & 912 & $<.0001$ \\
Maximum & 114 & 49 & \\
95th percentile & 12 & 9 & \\
75th percentile & 7 & 6 & \\
50th percentile & 5 & 4 & \\
25th percentile & 3 & 3 & \\
5th percentile & 0 & 0 & \\
Minimum & $32(134)$ & $15(45)$ & \\
Mean (SD) & & & $<.0001$ \\
Postoperative charges (dollars) & 735,597 & 745,157 & \\
Maximum & 179,053 & 106,844 & \\
95th percentile & 41,332 & 36,288 & \\
75th percentile & 23,605 & 20,126 & \\
50th percentile & 15,081 & 12,978 & \\
25th percentile & 10,863 & 9412 & \\
5th percentile & 1590 & 4905 & \\
Minimum & $47,898(78,759) 35,149(54,479)$ & \\
Mean (SD) &
\end{tabular}

EACA, Epsilon-aminocaproic acid; TXA, tranexamic acid; $S D$, standard deviation.

long-term outcomes. TXA has been noted to lower the seizure threshold, especially in patients post-CPB. ${ }^{25-27}$ This is plausible, given TXA has been demonstrated to bind to gamma-aminobutyric acid and glycine receptors. $^{15,16,27}$ There are also studies demonstrating the increased risk of seizure with TXA when compared with other antifibrinolytic agents. An increase incidence of postoperative seizures was noted when TXA was compared with aprotinin. In the study of Martin and colleagues ${ }^{25}$ (1188 patients), seizures occurred in $4.6 \%$ of patients receiving TXA and $1.2 \%$ of patients receiving aprotinin undergoing cardiac surgery with CPB. It is worth noting that in the analysis of Martin and colleagues, subjects were exposed to high doses of TXA as follows: " $2 \mathrm{~g}$ was administered at the beginning of CPB and then as a continuous infusion at a rate of $0.5 \mathrm{~g} / \mathrm{h}$ until chest closure; $2 \mathrm{~g}$ was added to the prime of the CPB equipment." ${ }^{25}$ Keyl and colleagues ${ }^{26}$ also demonstrated an increase in postoperative seizure risk within the first 24 hours in patients treated with TXA versus EACA undergoing aortic valve replacement $(6.4 \%$ vs $0.6 \%, P<.001)$. The protocol used by in the study by Keyl and colleagues also used a very high dose of TXA when compared with our protocol as, in their study, "TXA was administered at a dose of $100 \mathrm{mg} \mathrm{kg}^{-1}$ body weight. Half of the dose was added to the bypass circuit, half of the dose was given over approximately 1 hour starting after sternotomy along with the administration of heparin." 26 Furthermore, this result was not reproduced by Makhija and colleagues, ${ }^{8}$ who found no significant increase in seizure rates in a randomized control trial of TXA versus EACA in patients undergoing thoracic aortic surgery, or Falana and Patel $^{5}$ in a retrospective analysis of TXA versus EACA in 120 patients undergoing CPB. In comparison, the loading dose of TXA at our institution is weight based at $20 \mathrm{mg} / \mathrm{kg}$ and the maintenance rate is $2 \mathrm{mg} / \mathrm{kg} / \mathrm{h}$, and TXA maintenance dosing was also decreased according to serum creatinine (full protocol for TXA dosing can be seen in Appendix 1). EACA dosing protocol is a loading dose of $10 \mathrm{~g}, 10 \mathrm{~g}$ in the CPB prime, and the maintenance rate $2 \mathrm{~g} / \mathrm{h}$. Due to the fact that our study was underpowered for the rare outcome of seizure, we were unable to draw any conclusions regarding the risk of seizure in those patients treated with TXA verses EACA. We did not observe a significant increase in seizure risk; however, according to the package insert, "Tranexamic acid may cause seizures, including focal and generalized seizures."

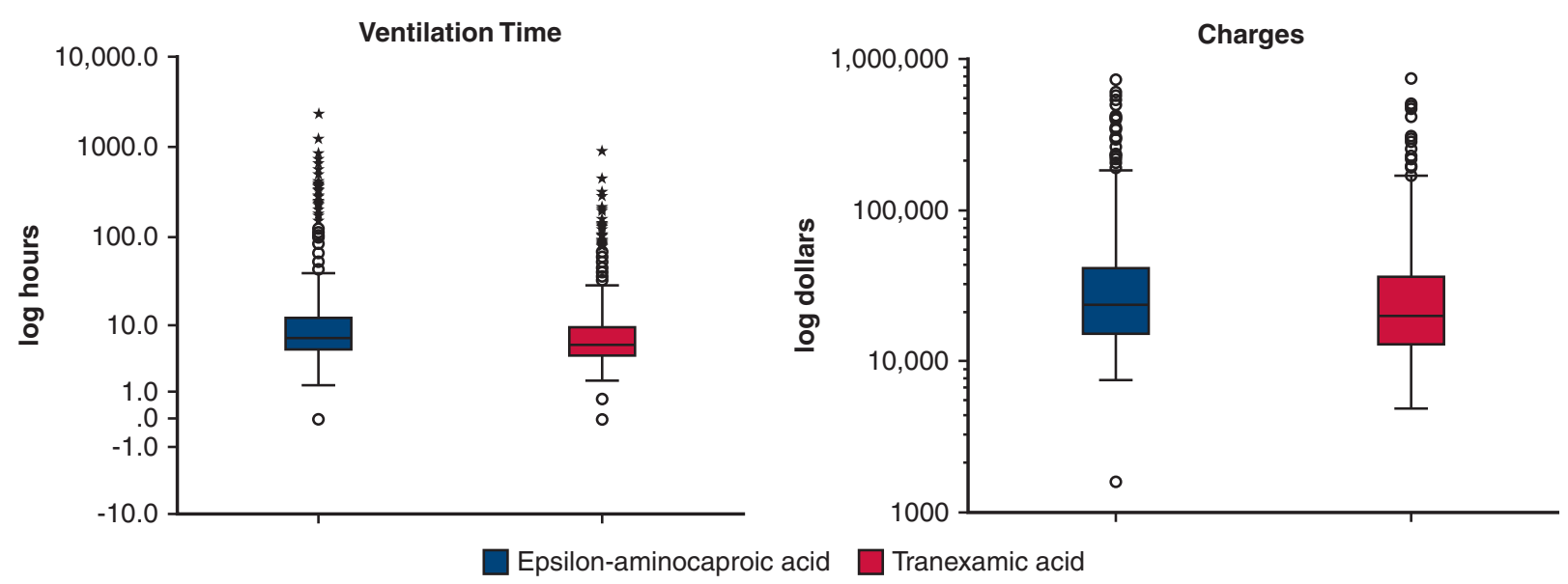

FIGURE 3. Boxplot of unadjusted median log data of ventilator time and charges comparing patients who received TXA or EACA. Black line is the median, the top of the box is the $75^{\text {th }}$ percentile, the bottom of the box is the 25 th percentile, the whiskers represent the maximum and minimum values excluding the outliers, and the circles represent the outliers. 
TABLE 6. Effect of TXA on rate of transfusion: negative binomial models, inverse probability of treatment weighting applied, controlling for surgeon

\begin{tabular}{lc}
\hline $\begin{array}{c}\text { Transfusion timing and type } \\
\text { (units) }\end{array}$ & $\begin{array}{c}\text { Rate ratio* }(\mathbf{9 5} \% \text { confidence } \\
\text { interval) } \mathbf{( T X A} \\
\text { compared with EACA) }\end{array}$ \\
\hline $\begin{array}{l}\text { Intraoperative and } \\
\text { postoperative } \\
\text { Red blood cells } \\
\text { Platelets }\end{array}$ & $0.97(0.78-1.22)$ \\
Fresh frozen plasma & $1.23(0.91-1.69)$ \\
Cryoprecipitate & $1.17(0.73-1.87)$ \\
Intraoperative & $0.61(0.26-1.45)^{*}$ \\
Red blood cells & \\
Platelets & $1.06(0.73-1.52)$ \\
Fresh frozen plasma & $0.79(0.57-1.09)^{*}$ \\
Cryoprecipitate & $1.01(0.56-1.79)$ \\
Postoperative & $0.69(0.13-3.60)^{*}$ \\
Red blood cells & \\
Platelets & $0.93(0.74-1.18)$ \\
Fresh frozen plasma & $1.49(0.96-2.31)$ \\
Cryoprecipitate & $1.25(0.67-2.35)$ \\
\hline
\end{tabular}

TXA, Tranexamic acid; EACA, Epsilon-aminocaproic acid. *Unable to control for surgeon due to quasi-separation.

Why the TXA group had a greater use of vasoconstrictors at the 48-hour mark is puzzling. In our database, we use vasoconstrictors at the 48-hour mark as a surrogate for vasoplegia. We have the following field to our local database: "two vasoconstrictors at 48 hours" to follow our progress with the management of vasoplegia, which has not changed despite our longstanding policy of discontinuing angiotensin-converting enzyme inhibitors and angiotensin receptor blockers 48 hours preoperatively in all patients.
Other authors have shown beneficial effects of TXA at the cellular level that are not demonstrated in our analysis. Effects such as the protection of the endothelial glycocalyx and suppression of damage associated molecular pattern release have been reported for TXA. In addition, in recent years, TXA has been shown to suppress post-traumatic inflammation both in hemorrhagic ${ }^{28,29}$ and non-hemorrhagic ${ }^{14}$ contexts. Although the comparison of anti-inflammatory capacities of TXA and EACA cannot be found in literature, in the case of EACA, it has been demonstrated that aprotinin suppressed the elevation of proinflammatory cytokine interleukin- 6 and metalloproteinase- 2 in the blood of CPB patients much stronger than EACA that barely exhibited any anti-inflammatory effect. ${ }^{30}$

TXA has been demonstrated to show cost savings when used in multiple settings, including orthopedic procedures and trauma surgery. ${ }^{6,9,10}$ However, there is little literature directly comparing the cost of TXA versus EACA, especially in cardiac surgery. One study of patients undergoing total joint arthroplasty compared cost of TXA versus EACA and showed a significant cost savings with TXA. ${ }^{10}$ Our findings demonstrate a small decrease in charges when using TXA in comparison with EACA (Tables 3 and 5 and Figure 3).

Our study was limited, given its retrospective and metachronous nature. Our ongoing registry collects carefully validated data prospectively. Although our study was neither randomized nor blinded, the "accident" of drug shortage that resulted in the change in drugs for all patients during a particular time interval resulted in an opportunity to compare groups in a retrospective manner. Given its design, our study may have been influenced by changes in practice other than use of TXA versus EACA, such as staffing changes or changes in procedures,

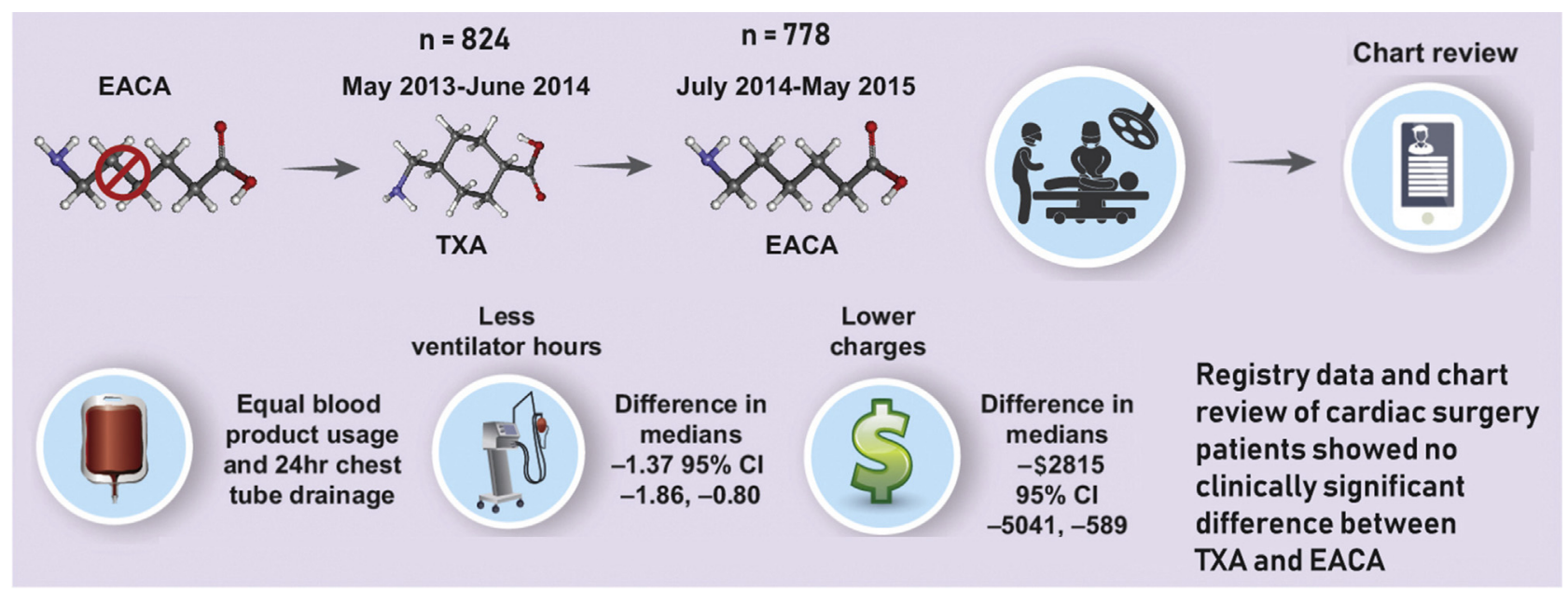

FIGURE 4. Subsequent to a shortage of EACA, TXA was used for a year after which EACA became available again. Comparing similar noncontemporaneous time periods using registry data and chart reviews, we found no difference between the outcome measures of chest tube drainage and blood products. Although there was a statistical difference with regard to hospital charges and ventilator time favoring TXA, the difference was not clinically significant. $E A C A$, Epsilon-aminocaproic acid; TXA, tranexamic acid; $C I$, confidence interval. 
management, and other process improvement initiatives in the time interval between the 2 arms. The majority of our sample was isolated CABG patients; however, nearly one half of patients underwent more complex cardiac surgeries, providing some generalizability to the cardiac surgery population.

\section{CONCLUSIONS}

A shortage of EACA allowed us to compare EACA with TXA. In summary, the major finding of this analysis is that TXA appears to be equivalent to EACA regarding antifibrinolytic effects during cardiac surgery with cardiopulmonary bypass. Patients treated with TXA had shorter ventilator times, and lower charges when compared with EACA that were statistically but not clinically significant (Figure 4).

\section{Conflict of Interest Statement}

The authors reported no conflicts of interest.

The Journal policy requires editors and reviewers to disclose conflicts of interest and to decline handling or reviewing manuscripts for which they may have a conflict of interest. The editors and reviewers of this article have no conflicts of interest.

\section{References}

1. Fergusson DA, Hebert PC, Mazer CD, Fremes S, MacAdams C, Murkin JM, et al. A comparison of aprotinin and lysine analogues in high-risk cardiac surgery. $N$ Engl J Med. 2008;358:2319-31.

2. Henry DA, Carless PA, Moxey AJ, O'Connell D, Stokes BJ, Fergusson DA, et al. Anti-Fibrinolytic use for minimizing perioperative allogeneic blood transfusion. Cochrane Database Syst Rev. 2011;3:CD001886.

3. Koster A, Schirmer U. Re-evaluation of the role of antifibrinolytic therapy with lysine analogs during cardiac surgery in the post aprotinin era. Curr Opin Anaesthesiol. 2011:24:92-7.

4. Vonk AB, Meesters MI, Schats J, Romijn JW, Jansen EK, Boer C. Removal of aprotinin from low-dose aprotinin/tranexamic acid antifibrinolytic therapy increases transfusion requirements in cardiothoracic surgery. Interact Cardiovasc Thorac Surg. 2011;12:135-9.

5. Falana O, Patel G. Efficacy and safety of tranexamic acid versus $\varepsilon$-aminocaproic acid in cardiovascular surgery. Ann Pharmacother. 2014;48:1563-9.

6. Gerstein NS, Brierley JK, Windsor J, Panikkath PV, Ram H, Gelfenbeyn KM, et al. Antifibrinolytic agents in cardiac and noncardiac surgery: a comprehensive overview and update. J Cardiothorac Vasc Anesth. 2017;31:2183-205.

7. Makhija N, Sarupria A, Kumar Choudhary S, Das S, Lakshmy R, Kiran U. Comparison of epsilon aminocaproic acid and tranexamic acid in thoracic aortic surgery: clinical efficacy and safety. J Cardiothorac Vasc Anesth. 2013;27:1201-7.

8. McCormack PL. Tranexamic acid: a review of its use in the treatment of hyperfibrinolysis. Drugs. 2012;72:585-617.

9. Pinto MA, Silva JG, Chedid AD, Chedid MF. Use of tranexamic acid in trauma patients: an analysis of cost-effectiveness for use in Brazil. Arq Bras Cir Dig. 2016;29:282-6.

10. Ramkumar DB, Ramkumar N, Tapp SJ, Moschetti WE. Pharmacologic hemostatic agents in total joint arthroplasty-a cost-effectiveness analysis. J Arthroplasty. 2018;33:2092-9.e9.

11. Diebel LN, Martin JV, Liberati DM. Early tranexamic acid administration ameliorates the endotheliopathy of trauma and shock in an in vitro model. J Trauma Acute Care Surg. 2017;82:1080-6.
12. Diebel ME, Martin JV, Liberati DM, Diebel LN. The temporal response and mechanism of action of tranexamic acid in endothelial glycocalyx degradation. J Trauma Acute Care Surg. 2018;84:75-80.

13. Jimenez JJ, Iribarren JL, Lorente L, Rodriguez JM, Hernandez D, Nassar I, et al Tranexamic acid attenuates inflammatory response in cardiopulmonary bypass surgery through blockade of fibrinolysis: a case control study followed by a randomized double-blind controlled trial. Crit Care. 2007;11:R117.

14. Carter DW, Prudovsky I, Kacer D, Soul T, Kumpel C, Pyburn K, et al. Tranexamic acid suppresses the release of mitochondrial damps and reduces lung inflammation in a murine burn model. J Trauma Acute Care Surg. 2019;86:617-24.

15. Furtmuller R, Schlag MG, Berger M, Hopf R, Huck S, Sieghart W, et al. Tranexamic acid, a widely used antifibrinolytic agent, causes convulsions by a gammaaminobutyric acid(a) receptor antagonistic effect. J Pharmacol Exp Ther 2002;301:168-73.

16. Lecker I, Wang DS, Whissell PD, Avramescu S, Mazer CD, Orser BA. Tranexamic acid-associated seizures: causes and treatment. Ann Neurol. 2016 79:18-26.

17. American Society of Anesthesiologists Task Force on Perioperative Blood Management. Practice guidelines for perioperative blood management: an updated report by the American Society of Anesthesiologists task force on perioperative blood management*. Anesthesiology. 2015;122:241-75.

18. Ferraris VA, Brown JR, Despotis GJ, Hammon JW, Reece TB, Saha SP, et al. 2011 update to the Society of Thoracic Surgeons and the Society of Cardiovascular Anesthesiologists blood conservation clinical practice guidelines. Ann Thorac Surg. 2011;91:944-82.

19. Mehta RL, Kellum JA, Shah SV, Molitoris BA, Ronco CC, Warnock DG, et al Acute kidney injury network: report of an initiative to improve outcomes in acute kidney injury. Crit Care. 2007:11:R31.

20. Austin PC, Stuart EA. Moving towards best practice when using inverse probability of treatment weighting (IPTW) using the propensity score to estimate causal treatment effects in observational studies. Stat Med. 2015;34:3661-79.

21. Munoz JJ, Birkmeyer NJ, Birkmeyer JD, O’Connor GT, Dacey LJ. Is epsilonaminocaproic acid as effective as aprotinin in reducing bleeding with cardiac surgery? A meta-analysis. Circulation. 1999;99:81-9.

22. Raghunathan K, Connelly NR, Kanter GJ. Epsilon-aminocaproic acid and clinical value in cardiac anesthesia. J Cardiothorac Vasc Anesth. 2011;25:16-9.

23. Maineri P, Covaia G, Realini M, Caccia G, Ucussich E, Luraschi M, et al. Postoperative bleeding after coronary revascularization: comparison between tranexamic acid and epsilon aminocaproic acid, Minerva Cardioangiol 2000;48: 155-60.

24. Koster A, Faraoni D, Levy JH. Antifibrinolytic therapy for cardiac surgery: an update. Anesthesiology. 2015;123:214-22.

25. Martin K, Wiesner G, Breuer T, Lange R, Tassani P. The risks of aprotinin and tranexamic acid in cardiac surgery: a one-year follow-up of 1188 consecutive patients. Anesth Analg. 2008;107:1783-90.

26. Keyl C, Uhl R, Beyersdorf F, Stampf S, Lehane C, Wiesenack C, et al. High-dose tranexamic acid is related to increased risk of generalized seizures after aortic valve replacement. Eur J Cardiothorac Surg. 2011;39:e114-21.

27. Schwinn DA, Mackensen GB, Brown EN. Understanding the TXA seizure connection. J Clin Invest. 2012;122:4339-41.

28. Teng Y, Feng C, Liu Y, Jin H, Gao Y, Li T. Anti-inflammatory effect of tranexamic acid against trauma-hemorrhagic shock-induced acute lung injury in rats Exp Anim. 2018;67:313-20.

29. Peng Z, Kechen B, LeBlanc A, Kozar R. Intraluminal tranexamic acid inhibits intestinal sheddases and mitigates gut and lung injury and inflammation in a rodent model of hemorrhagic shock. J Trauma Acute Care Surg. 2016;81: 358-65.

30. Dorman B, Stroud R, Wyckoff M, Zellner J, Botta D, Leonardi A, et al. Differential effects of epsilon-aminocaproic acid and aprotinin on matrix metalloproteinase release in patients following cardiopulmonary bypass. J Cardiovasc Pharmacol. 2008;51:415-23.

Key Words: cardiopulmonary bypass, perioperative care, pharmacology (antifibrinolytic), blood (coagulation/anticoagulation), bleeding control, and hematology 


\section{APPENDIX 1. TRANEXAMIC ACID DOSING FOR CARDIAC SURGERY}

1. Tranexamic acid concentration of $40 \mathrm{mg} / \mathrm{mL}$ in normal

3. Set rate to deliver loading dose over 20 minutes saline

4. Once loading dose completed, set maintenance rate

2. Find patient weight in chart below according to renal function

\begin{tabular}{|c|c|c|c|c|}
\hline \multicolumn{5}{|c|}{ Normal renal function (serum creatinine $<1.6 \mathrm{mg} / \mathrm{dL}$ ) } \\
\hline Patient weight, kg & $\begin{array}{c}\text { Loading dose, } \mathrm{mg} \\
(20 \mathrm{mg} / \mathrm{kg})\end{array}$ & $\begin{array}{c}\text { Loading rate }(\mathrm{mL} / \mathrm{h}) \\
\text { give over } 20 \mathrm{~min}\end{array}$ & Volume to deliver, $\mathbf{m L}$ & $\begin{array}{l}\text { Maintenance rate } \\
(\mathrm{mL} / \mathrm{h}) 2 \mathrm{mg} / \mathrm{kg} / \mathrm{h}\end{array}$ \\
\hline 40 & 800 & 60 & 20 & 2 \\
\hline 50 & 1000 & 75 & 25 & 2.5 \\
\hline 60 & 1200 & 90 & 30 & 3 \\
\hline 70 & 1400 & 105 & 35 & 3.5 \\
\hline 80 & 1600 & 120 & 40 & 4 \\
\hline 90 & 1800 & 135 & 45 & 4.5 \\
\hline 100 & 2000 & 150 & 50 & 5 \\
\hline 110 & 2200 & 165 & 55 & 5.5 \\
\hline 120 & 2400 & 180 & 60 & 6 \\
\hline 130 & 2600 & 195 & 65 & 6.5 \\
\hline 140 & 2800 & 210 & 70 & 7 \\
\hline \multicolumn{5}{|c|}{ Serum creatinine $1.6-3.3 \mathrm{mg} / \mathrm{dL}$} \\
\hline Patient weight, kg & $\begin{array}{l}\text { Loading dose, mg } \\
(20 \mathrm{mg} / \mathrm{kg})\end{array}$ & $\begin{array}{c}\text { Loading rate }(\mathrm{mL} / \mathrm{h}) \\
\text { give over } 20 \mathrm{~min}\end{array}$ & Volume to deliver, $\mathrm{mL}$ & $\begin{array}{l}\text { Maintenance rate } \\
(\mathrm{mL} / \mathrm{h}) 1.5 \mathrm{mg} / \mathrm{kg} / \mathrm{h}\end{array}$ \\
\hline 40 & 800 & 60 & 20 & 1.5 \\
\hline 50 & 1000 & 75 & 25 & 1.9 \\
\hline 60 & 1200 & 90 & 30 & 2.3 \\
\hline 70 & 1400 & 105 & 35 & 2.6 \\
\hline 80 & 1600 & 120 & 40 & 3 \\
\hline 90 & 1800 & 135 & 45 & 3.4 \\
\hline 100 & 2000 & 150 & 50 & 3.8 \\
\hline 110 & 2200 & 165 & 55 & 4.1 \\
\hline 120 & 2400 & 180 & 60 & 4.5 \\
\hline 130 & 2600 & 195 & 65 & 4.9 \\
\hline 140 & 2800 & 210 & 70 & 5.3 \\
\hline \multicolumn{5}{|c|}{ Serum creatinine $3.3-6.6 \mathrm{mg} / \mathrm{dL}$} \\
\hline Patient weight, kg & $\begin{array}{c}\text { Loading dose, } \mathrm{mg} \\
(20 \mathrm{mg} / \mathrm{kg})\end{array}$ & $\begin{array}{c}\text { Loading rate }(\mathrm{mL} / \mathrm{h}) \\
\text { give over } 20 \mathrm{~min}\end{array}$ & Volume to deliver, $\mathbf{m L}$ & $\begin{array}{l}\text { Maintenance rate } \\
(\mathrm{mL} / \mathrm{h}) 1 \mathrm{mg} / \mathrm{kg} / \mathrm{h}\end{array}$ \\
\hline 40 & 800 & 60 & 20 & 1 \\
\hline 50 & 1000 & 75 & 25 & 1.3 \\
\hline 60 & 1200 & 90 & 30 & 1.5 \\
\hline 70 & 1400 & 105 & 35 & 1.8 \\
\hline
\end{tabular}


Continued

\begin{tabular}{|c|c|c|c|c|}
\hline \multicolumn{5}{|c|}{ Serum creatinine $3.3-6.6 \mathrm{mg} / \mathrm{dL}$} \\
\hline Patient weight, kg & $\begin{array}{c}\text { Loading dose, } \mathrm{mg} \\
(20 \mathrm{mg} / \mathrm{kg})\end{array}$ & $\begin{array}{l}\text { Loading rate }(\mathrm{mL} / \mathrm{h}) \\
\text { give over } 20 \mathrm{~min}\end{array}$ & Volume to deliver, $\mathbf{m L}$ & $\begin{array}{l}\text { Maintenance rate } \\
(\mathrm{mL} / \mathrm{h}) 1 \mathrm{mg} / \mathrm{kg} / \mathrm{h}\end{array}$ \\
\hline 80 & 1600 & 120 & 40 & 2 \\
\hline 90 & 1800 & 135 & 45 & 2.3 \\
\hline 100 & 2000 & 150 & 50 & 2.5 \\
\hline 110 & 2200 & 165 & 55 & 2.8 \\
\hline 120 & 2400 & 180 & 60 & 3 \\
\hline 130 & 2600 & 195 & 65 & 3.3 \\
\hline 140 & 2800 & 210 & 70 & 3.5 \\
\hline \multicolumn{5}{|c|}{ Serum creatinine $>6.6 \mathrm{mg} / \mathrm{dL}$} \\
\hline Patient weight, kg & $\begin{array}{c}\text { Loading dose, mg } \\
(20 \mathrm{mg} / \mathrm{kg})\end{array}$ & $\begin{array}{l}\text { Loading rate }(\mathrm{mL} / \mathrm{h}) \\
\text { give over } 20 \mathrm{~min}\end{array}$ & Volume to deliver, $\mathrm{mL}$ & $\begin{array}{l}\text { Maintenance rate } \\
(\mathrm{mL} / \mathrm{h}) 0.5 \mathrm{mg} / \mathrm{kg} / \mathrm{h}\end{array}$ \\
\hline 40 & 800 & 60 & 20 & 0.5 \\
\hline 50 & 1000 & 75 & 25 & 0.6 \\
\hline 60 & 1200 & 90 & 30 & 0.8 \\
\hline 70 & 1400 & 105 & 35 & 0.9 \\
\hline 80 & 1600 & 120 & 40 & 1 \\
\hline 90 & 1800 & 135 & 45 & 1.1 \\
\hline 100 & 2000 & 150 & 50 & 1.3 \\
\hline 110 & 2200 & 165 & 55 & 1.4 \\
\hline 120 & 2400 & 180 & 60 & 1.5 \\
\hline 130 & 2600 & 195 & 65 & 1.6 \\
\hline 140 & 2800 & 210 & 70 & 1.8 \\
\hline
\end{tabular}

